Ozone climatology

\section{More news from Antarctica}

\section{Susan Solomon}

Much effort has been directed towards obtaining a better understanding of the spectacular modification of the Antarctic ozone layer called the ozone 'hole', a precipitous drop in total ozone abundance that has appeared over Antarctica each austral spring (September and October) since about 1975 . Forty-five papers on the subject appeared in a special issue of Geophysical Research Letters in November 1986. The National Ozone Expedition observational campaign was carried out by 18 scientists (of which I was one) at the National Science Foundation's McMurdo Station during austral spring 1986, and its preliminary results were discussed ${ }^{1}$ in a recent News and Views article. The first paper on the results from the expedition, by Hofmann and collaborators, appears on page 59 of this issue ${ }^{2}$.

The phenomenon of the ozone hole was first identified ${ }^{3}$ by scientists from the British Antarctic Survey, based on a 30-year record of total ozone measurements at Halley Bay, Antarctica. These data suggested ${ }^{4}$ that the total ozone concentration should remain rather constant during Antarctic spring, and indeed, such a seasonal cycle was observed ${ }^{3}$ before about 1975. The recent data display a different, clearly anomalous, seasonal trend. Further, the magnitude for the spring decline is generally greater from one year to the next, although some year-to-year fluctuations are also observed. Contemporary total ozone abundances in Antarctica in October are only about half as large as those obtained ${ }^{3}$ between 1950 and the early 1970 s. This is the largest, statistically significant perturbation to a monthly averaged ozone climatology ever recorded.

It is beyond the scope of this article to review the current status of the rapidly growing subject of research on the ozone hole. Instead I will discuss representative rather than comprehensive references. There are several plausible hypotheses ${ }^{5-8}$ that seek to explain the observed behaviour of the ozone column. Each results in total ozone changes that are broadly consistent with observations, but each has rather different implications for dynamical tracers; for other chemical species such as nitrogen dioxide, chlorine nitrate or chlorine oxide; and for the vertical structure of the ozone column change. Detailed observations of these parameters and further laboratory studies will be needed before a definitive theory of the ozone change can be advanced. Recent studies provide some interesting insights and apparent contradictions in the behaviour of the Antarctic stratosphere.
It is of great interest to ascertain whether a temperature trend has accompanied the observed ozone trend, because both dynamical and chemical processes (particularly those occurring in polar stratospheric clouds ${ }^{5,6}$ ) are expected to be closely linked to temperatures. Meteorological analyses ${ }^{9}$ based mainly on satellite data display a temperature change as large as $18^{\circ} \mathrm{C}$ based on a rather limited time series dating only from 1979 to 1985 . On the other hand, a detailed analysis ${ }^{10}$ of radiosonde data encompassing the period 1958-1985 suggests a much smaller, but statistically significant trend of about 6$8{ }^{\circ} \mathrm{C}$. The differences between the two datasets are thus quite large and perhaps contradictory, requiring further investigation. Such a trend would be of great importance if substantiated, as it would represent a significant departure from temperature climatology, just as the ozone hole itself is a verified and extreme departure from ozone climatology. Could such a temperature change be unambiguously assigned as the cause, or as an effect, of the observed change in ozone? Radiative transfer theory suggests ${ }^{11}$ that the observed change in ozone could lead to a $5-15^{\circ} \mathrm{C}$ change, but it seems clear that a significant change in dynamics could yield perturbed temperature and possibly ozone distributions.

A useful database on Antarctic nitrogen dioxide from studies ${ }^{12}$ by a New Zealand group, is also available. These data display unusually low abundances during Antarctic spring. Like ozone, the seasonal cycle of nitrogen dioxide is in marked disagreement with conventional theory ${ }^{5}$, demonstrating that the chemistry of the Antarctic spring stratosphere is highly anomalous. Further observations of chemical species are needed to determine whether these anomalies are directly associated with the ozone anomaly.

The paper by Hofmann and colleagues in this issue ${ }^{2}$ reports a series of ozonesonde observations carried out as part of the National Ozone Expedition. These data provide several important insights into the problem of the ozone hole. Perhaps the most significant is their demonstration that the seasonal decline in the total ozone column is largely confined to the region from about 12 to $20 \mathrm{~km}$. The observed timescale for the ozone change was very short, only about a month. The bulk of the depletion of the total column occurred in September, challenging most of the existing ozone depletion hypotheses ${ }^{5-8}$, which can more readily account for a change in October. The total ozone levels in October were affected by substantial increases in ozone near the $24-30-\mathrm{km}$ level, which were associated with planetary wave activity at these upper levels. Year-to-year variations in the October total column abundance may reflect such variations in upper level dynamics even as lower altitudes suffer further depletion.

Also important is the observation ${ }^{2}$ of restricted layers in which dramatic depletions of the local ozone abundance had occurred, making important contributions to the integrated column change. The layers were typically a few kilometres in thickness, and many structures repeated on consecutive soundings, demonstrating that they are not an instrumental artefact. On one occasion in October a local depletion of more than 90 per cent was observed in a layer a few kilometres thick at $60 \mathrm{mbar}$ (note that the observed depletion of the integrated column on this date was about 50 per cent). Aerosol measurements on the same flight showed no evidence of corresponding layers that would probably be associated with a dynamical explanation of this phenomenon. On the other hand, previous chemical hypotheses proposed to date do not suggest such large, local ozone depletions. Hofmann et al. suggest ${ }^{2}$ that the layered structure is associated with chemical reactions following the evaporation of polar stratospheric clouds. These observations may represent the greatest clue and challenge to the mystery of the cause of the ozone hole.

It seems clear that much further research is needed to clarify the cause of this remarkable phenomenon. The Antarctic temperature climatology is of prime importance. Further observations of chemical species, in addition to nitrogen dioxide and ozone, are badly needed, both from the ground and in situ. Dynamical tracers such as nitrous oxide and methane should be measured, and laboratory studies of heterogenous reactions and chlorine chemistry carried out. In situ observations of a range of chemical species inside one of the observed layers of spectacular local depletion would undoubtedly add much to the understanding of their origin.

1. Margitan, J.J. Nature 325, 297-298 (1987)

2. Hofmann, D.J., Harder, J.W., Rolf, S. R. \& Rosen, J. M Nature 326, 59-62 (1987)

Farman, J.C., Gardiner, B.G. \& Shanklin, J.D. Nature 315, 207-210 (1985)

4. Cariolle, D., Deque, M. \& Morcrette, J. J. Geophys. Res. Lett. 13, 1304-1307 (1986)

Solomon, S. et al. Nature 321, 755-758 (1986).

6. McElroy, M.B. et al. Nature 321, $759-762$ (1986)

7. Callis, L.B. \& Natarajan, M. J. geophys. Res. 91, 10771 10796 (1986)

Tung,K.K. et al. Nature 333, 811-814 (1986)

9. Newman. P.A. \& Schoeberl, M.R. Geophys. Res. Lett. 13. 1206-1209 (1986)

10. Angell, J. K. Geophys. Res. Lett. 13, 1240-1243 (1986)

11. Shine, K. P. Geophys. Res. Lett. 13, 1331-1334 (1986)

12. Keys, J.G. \& Johnston, P. V. Geophys. Res. Lett. 13, 1260 1263 (1986).

Susan Solomon is in the Environmental Research Laboratories of the National Oceanographic and Atmospheric Administration, Boulder, Colorado 80303, USA. 